\title{
THE JOURNAL OF PHILOSOPHY
}

VOLUME GV, NO. 2, FEBRUARY 2008

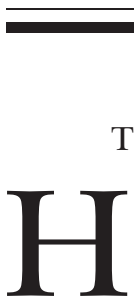

\section{THE SITUATION-DEPENDENCY OF PERCEPTION*}

lighting conditions, and similar features of the environment that determine the way objects are presented. Despite this fact, we can perceive the shape and color of objects. ${ }^{1}$ We can perceive the shape of objects although only the facing surfaces are visible, and we can perceive two same-sized objects located at different distances to be the same size. Similarly, we can perceive the uniform color of a yellow wall although parts of it are illuminated more brightly than others, and we can recognize the sound of a cello regardless of whether it is played on a street or in a concert hall. More generally, subjects can perceive the properties objects have regardless of the situational features, although the way an object is presented always depends on the situational features.

When I speak of objects without further qualification, I mean mindindependent, external objects, such as cats and tables. Let us call the properties that an object has regardless of the situational features the intrinsic properties of the object. An intrinsic property of an object is a

* I am indebted to Keith Allen, Robert Audi, Stephen Engstrom, Alan Hájek, Benj Hellie, Anjana Jacob, James John, Uriah Kriegel, William Lycan, Mohan Matthen, Anders Nes, Gurpreet Rattan, Sydney Shoemaker, Declan Smithies, Evan Thompson, Timothy Williamson, Wayne $\mathrm{Wu}$, and the members of the Australian National University philosophy of mind reading group for comments on a draft of this paper. Special thanks are due to David Chalmers, Anil Gupta, John McDowell, and Jonathan Schaffer. I am also grateful to members of audiences at the ANU, University of Oslo, University of Oxford, and Rutgers University-in particular Herman Cappelen, Bill Fish, Jason Stanley, Fiona Macpherson, and Kim Sterelny. Thanks finally to the Norwegian Research Council for generous funding while I was writing this paper.

${ }^{1}$ Of course, there are breakdown conditions. One cannot, for instance, tell whether a shape is a sphere or a cube, if one perceives it from sufficiently close up. 
property that does not depend on the object's relations to other individuals distinct from itself. The intrinsic properties that are of relevance to the current discussion are the perceivable intrinsic properties. $^{2}$ Let us call the features of the environment that determine the way an object is presented the situational features. The lighting conditions and the subject's location in relation to perceived objects are the situational features that are typically the most salient for the ways objects are presented-at least for human visual perception.

If the way an object is presented always depends on the situational features, then an explanation is needed for how one can have knowledge of the intrinsic properties of objects through perception. The aim of this paper is to contribute to such an explanation. The main thesis is that perceptual experience is necessarily situationdependent. Call this the situation-dependency thesis. In short the idea is that the way an object is must not just be distinguished from the way it appears and the way it is represented, but also from the way it is presented given the situational features. I argue that the way an object is presented is best understood in terms of external, mindindependent, but situation-dependent properties that the object

\footnotetext{
${ }^{2}$ For a discussion of intrinsic properties, see Brian Weatherson, "Intrinsic vs. Extrinsic Properties," in Edward Zalta, ed., The Stanford Encyclopedia of Philosophy (2006). In the context of the present discussion, I take for granted that colors are external, mind-independent, and intrinsic properties of surfaces, solids, or light. For a defense of colors as intrinsic properties, see Alex Byrne and David Hilbert, "Color Primitivism," in Ralph Schumacher, ed., Perception and the Status of Secondary Qualities (Boston: Kluwer, forthcoming). My argument is agnostic on the different possible ways of treating colors as mind-independent properties. So it is agnostic on views according to which colors are reflectance properties and so-called primitivist and naïve realist accounts of colors. For a defense of an understanding of colors as reflectance properties, see Mohan Matthen, "Biological Functions and Perceptual Content," this Journal, Lxxxv, 1 (January 1988): 5-27; and Byrne and Hilbert, "Color Realism and Color Science," Behavioral and Brain Sciences, Xxvi, 1 (February 2003): 3-21. For critical discussions, see C.L. Hardin, Color for Philosophers: Unweaving the Rainbow (Indianapolis: Hackett, 1988); and Brian McLaughlin, "Color, Consciousness, and Color Consciousness," in Aleksander Jokiç and Quentin Smith, eds., New Essays on Consciousness (New York: Oxford, 2003), pp. 97-154. For a defense of a naïve realist view of color, see John Campbell, "A Simple View of Colour," in John Haldane and Crispin Wright, eds., Reality: Representation and Projection (New York: Oxford, 1993), pp. 257-68. Colors understood in terms of dispositional properties are often considered to be mind-independent; for example, Sydney Shoemaker, "On the Way Things Appear," in Tamar Gendler and John Hawthorne, eds., Perceptual Experience (New York: Oxford, 2006), pp. 461-80. Similarly, views that analyze what it is for something to be colored in terms of what it is for something to look colored are sometimes considered to be compatible with the idea that colors are mindindependent; for example, Alva Noë, Action in Perception (Cambridge: MIT, 2004). Insofar as such accounts treat colors in terms of experiences of color, they are just a version of the view that colors are mind-dependent properties. For an excellent defense of this thesis, see Keith Allen, "The Mind-Independence of Colour," European Journal of Philosophy (forthcoming).
} 
has given its intrinsic properties and the situational features. ${ }^{3}$ I will spell out the situation-dependency thesis in terms of the idea that perception represents situation-dependent properties. To a first approximation, situation-dependent properties are extrinsic, mindindependent properties that are exclusively sensitive to and ontologically dependent on intrinsic properties and the situational features. They play a pivotal epistemic role insofar as the perception of intrinsic properties is epistemically dependent on the representation of situation-dependent properties. By arguing for this epistemic dependency, I aim to establish that the situation-dependency of perception is a desideratum for any account of perception.

My argument has three parts. First, I argue for the situationdependency thesis. Second, I show that perception of the intrinsic properties of objects is epistemically dependent on representations of situation-dependent properties. Third, I argue that recognizing the situation-dependency thesis makes it possible to acknowledge that objects are presented a certain way, while holding on to the intuition that subjects directly perceive physical objects. Before I embark on this project it will be helpful to motivate the situationdependency thesis in light of standard views of perception.

\section{BACKGROUND}

Traditionally, the way an object is presented given the situational features has been downplayed or conflated with either the way the object appears to one (which is a matter of the phenomenology of perception) or with the way one represents the object (which is a matter of perceptual content). ${ }^{4}$ Views that downplay the fact that objects are presented a certain way given the situational features insist that subjects perceive the intrinsic properties of objects directly. If we perceive intrinsic properties directly, then it would seem that there is no need to appeal to what I call situation-dependent properties.

\footnotetext{
${ }^{3}$ This use of the phrase that objects are presented in a certain way must be distinguished from the use of the phrase that picks out a subjective, sensational property of experience. John McDowell writes of the determinateness with which shades of colors "are presented in one's visual experience"-Mind and World (Cambridge: Harvard, 1994), p. 56. What McDowell has in mind here is a particular phenomenon of the sensible qualities of experience. McDowell's idea of something being presented in one's visual experience must be distinguished from the idea I am concerned with, namely the idea of the way objects are presented understood in terms of the mindindependent, situation-dependent properties of objects.

${ }^{4}$ Appearances have in turn been understood in terms of the way an object is perceived, the way it is given in experience, the way it is presented in one's visual experience, or some other mind-dependent property of experience. These notions differ substantially, but all concern the phenomenology of experience.
} 
Against such naïve direct realist views, ${ }^{5} \mathrm{I}$ argue that if we take seriously how subjects gain knowledge through perception, we must acknowledge that the way an object is presented depends on the situational features. I will argue that it follows from this that perceptual knowledge of intrinsic properties is epistemically dependent on representing the relevant situation-dependent properties. If this is right, then the question of how subjects can have perceptual knowledge of objects cannot be answered by insisting that we perceive intrinsic properties directly.

A second influential line of thought in the philosophy of perception is to understand the ways objects are presented given the situational features as mind-dependent. This line of thought goes back to Locke, Berkeley, and Hume. Hume writes: "[T] he table, which we see, seems to diminish, as we remove farther from it: but the real table, which exists independent of us, suffers no alteration: it was, therefore, nothing but its image, which was present to the mind." ${ }^{6}$ By presupposing that the appearance of an object is a case of an illusion, Hume is led to conclude that appearances are mind-dependent items of sorts. The thought that there is something present to the mind that is distinct from the perceived object has motivated different versions of phenomenalism, sensedata theories, and indirect realism. ${ }^{7}$ The details of these views differ radically, in particular with respect to the ontological and epistemological status of that which is directly present to the mind. What the views in this tradition have in common is the thesis that what is directly present to consciousness is a mind-dependent property or object rather than a property of the physical object that the perception is of. ${ }^{8}$

\footnotetext{
${ }^{5}$ It is important to distinguish "naïve direct realism" from "naïve realism" as defended, for example, by Michael Martin, "The Reality of Appearances," in Mark Sainsbury, ed., Thought and Ontology (Milan, Italy: Franco Angeli, 1997), pp. 81-106. The former is a thesis about the direct object of perception; the latter is a thesis about the mind-independence of the objects, properties, and relations that we perceive.

${ }^{6}$ Hume, "An Enquiry concerning Human Understanding," in Enquiries Concerning Human Understanding and Concerning the Principles of Morals, L.A. Selby-Bigge and P.H. Nidditch, eds. (New York: Oxford, 1975), p. 152.

${ }^{7}$ H.H. Price famously argues that sense-data are mind-dependent, nonphysical objects. See his Perception (London, UK: Methuen, 1950, first published 1932). Frank Jackson defends the existence of nonphysical sense-data on the basis of linguistic analysis. See his Perception (New York: Cambridge, 1977). He interprets the claim "object $x$ looks red" as having the underlying form, "Subject $S$ sees a red sense-datum belonging to $x$." More recently, he has distanced himself from his unabashed sensedata view. See his From Metaphysics to Ethics (New York: Oxford, 1998). I follow A.D. Smith in treating sense-data theories as a version of indirect realism. See his The Problem of Perception (Cambridge: Harvard, 2002).

${ }^{8}$ This thesis is compatible with the claim that the intentional object of perception is an external, mind-independent object and with the claim that perceptual content represents (possibly among other things) external and mind-independent objects.
} 
Against the views in this tradition, I argue that at least part of what is typically understood as mind-dependent should be understood in terms of the situation-dependency of perception. In short, the idea is that the ways objects are presented are best understood as external, mind-independent, but situation-dependent properties of the object. Understanding the ways objects are presented as external and mind-dependent makes it possible to distinguish between the subjective aspect of perception, on the one hand, and its objective, but situation-dependent aspect on the other.

The distinction between the subjective and objective properties of perception has been understood in many different ways, but all concern the dependence or independence of perception on the subject's sensibility or cognition. In the idealist tradition, the distinction is understood to mark the extent to which subjects perceive reality independently of their sensibility or cognition. Insofar as perception is subjective, perception is understood to be constitutive of its object. In the phenomenological tradition, the distinction is understood to mark the extent to which the object of phenomenal consciousness is mind-dependent.

Phenomenalism, indirect realism, and direct realism differ with respect to what constitutes the object of perception. The question of what perception is of and what perception represents must be distinguished from the question of how the relationship between the representational content and the phenomenology of experience is conceived. The argument presented here is agnostic on the answer to the second question. If the argument holds at all, it will hold regardless of how the debate on the relation between the representational content and the phenomenology of experience is resolved. The present discussion does however relate to that debate insofar as I argue that at least part of what is often conceived of only in terms of the phenomenology of experience should be thought of, at least in part, in terms of representations of external, mind-independent properties of objects. This by no means amounts to a denial of nonrepresentational appearance properties. As I will argue in the next section, the thesis that perception involves representations of situationdependent properties is compatible with these properties being accompanied by appearance properties.

\section{THE ARGUMENT FOR THE SITUATION-DEPENDENCY THESIS}

Phenomenalists and indirect realists treat the ways objects appear as something mind-dependent. There are no doubt mind-dependent ways that objects appear. However one understands these minddependent ways that objects appear, I will argue that experience represents the mind-independent ways that objects are presented given 
the situational features. The way an object is presented can be understood strictly externally, namely as determined by the object's intrinsic properties and the situational features. ${ }^{9}$ For the visual perception of size and shape, the perceiver's location in relation to the perceived object is the crucial situational feature that determines how the object is presented. For the perception of color, the lighting conditions and color context are among the crucial situational features.

If the way an object is presented is understood as external and mind-independent, it can be understood in terms of the properties the object has given the situational features, that is, the object's situation-dependent properties. ${ }^{10}$ Situation-dependent properties are (nonconstant) functions of the intrinsic properties of the object and the situational features. This means that fixing the intrinsic properties and the situational features fixes the situation-dependent properties. Furthermore, situation-dependent properties are ontologically dependent on and exclusively sensitive to intrinsic properties and situational features. ${ }^{11}$

It will be helpful to consider some examples. Take the cup on my table. It is presented in a certain way given my location. One side

\footnotetext{
${ }^{9}$ This thesis draws on several well-known concepts: Noë's (op. cit.) notion of Pproperties and Christopher Peacocke's notion of a scene-A Study of Concepts (Cambridge: MIT, 1992), see especially chapter 3. As I show below, situation-dependent properties can be understood as the properties constituting scenes. I discuss Noë's view in my "Action and Self-Location in Perception," Mind, cxvi, 463 (July 2007): 603-32. In brief, Noë understands P-properties as projections on a plane perpendicular to the subject's line of sight. Although he insists that they are objective, mind-independent properties, he analyzes them in terms of how things look to perceivers, more specifically in terms of what he calls phenomenal objectivism and in terms of the psychological notion of a visual field. In this respect, they are the very same kind of properties that James J. Gibson refers to as visual field properties and Peacocke refers to as sensational properties. See Gibson, The Perception of the Visual World (Boston: Houghton Mifflin, 1950); and Peacocke, "Sensational Properties: Theses to Accept and Theses to Reject," in Revue Internationale de Philosophie, in a special issue on the Philosophy of Mind edited by Joëlle Proust (forthcoming). For a defense of this thesis, see Allen, "Being Coloured and Looking Coloured" (manuscript). Matthen argues for an idea that is similar to Noë's-Seeing, Doing, and Knowing (New York: Oxford, 2005). According to Matthen, a surface is presented as it is-color-wise-in part because of a property it has, its color, and in part because of the condition it is in. In contrast to P-properties, situationdependent properties are not analyzed in terms of how things look. Furthermore, they are not properties of the visual field and are not two-dimensional geometrical projections. However, as I will argue, recognizing situation-dependent properties is compatible with there being properties that capture how things look.

${ }^{10}$ An alternative label might be "relational properties." But relational properties have been understood as properties that involve relations to a perceiver's mind. For discussion, see Evan Thompson, Colour Vision (New York: Routledge, 1995). Since the properties I am introducing are a function only of external, mind-independent features it is important to distinguish them clearly from such relational properties.

${ }^{11}$ Thanks to Alan Hájek for helpful discussions about different ways of understanding relations of ontological dependence.
} 
is closer than the other; one part faces away from me. Its shape is presented in an egocentric frame of reference, which in turn means that the object and its parts are presented as standing in specific spatial relations to me. The way the cup is presented to a location is on the suggested view an external and mind-independent, albeit situation-dependent property of the world. Any perceiver occupying the same location would, ceteris paribus, be presented with the cup in the very same way. Similarly, the way the color of the cup is presented is the way its intrinsic color property manifests itself given the current lighting conditions. If the intrinsic color property is conceived of as a reflectance property, then the correlating situation-dependent property will be a wavelength emittence property.

It is conceivable that two objects with different intrinsic properties can have the very same situation-dependent property given suitable situational features. So it is conceivable that, say, a blue couch under yellow lighting conditions has the very same situation-dependent color property as a green couch under standard lighting conditions. Furthermore, the thesis that there is a distinction between the situation-dependent properties and the intrinsic properties of an object is compatible with the existence of cases in which the situationdependent and intrinsic properties of an object match. Say I am looking at the round rim of a cup from directly above. From such a location, the rim of the cup is presented as round. But even in this case, there is a metaphysical distinction between the two properties. The important point is that given the spatiotemporal nature of perception, ${ }^{12}$ there is a distinction between the way an object is presented and the way it is regardless of the situational features. In other words, there is a distinction between the situation-dependent and the intrinsic properties of an object.

The idea of situation-dependent properties can be understood in terms of Christopher Peacocke's notion of a scene. A scene is "the volume of the real world around the perceiver at the time of the experience, with an origin and axes in the real world fixed in accordance with the labeling of the scenario."13 The scenario is a way of locating objects, properties, and relations in relation to a labeled origin and axes. The elements of a scene can be understood as situation-dependent spatial properties. An object is presented in different ways to different locations in a world and it is an objective mind-independent feature of the object that it is so presented. Since situation-dependent spatial properties are location-relative properties rather than perceiver-relative

\footnotetext{
${ }^{12}$ I elaborate on this spatiotemporal nature of perception in section III.

${ }^{13}$ Peacocke, A Study of Concepts, p. 64.
} 
properties, any perceiver occupying the same location is, ceteris paribus, presented with the very same situation-dependent spatial properties.

The distinction between a scene and a world that is not locationrelative is, however, only helpful to bring out the contrast between intrinsic spatial properties and the correlating situation-dependent properties. It is not helpful to bring out the contrast between intrinsic colors or sounds and the correlating situation-dependent properties. The reason is that the situational features relevant for perceiving spatial properties is location-relative (for instance, the distance from the perceiver and the orientation relative to the perceiver), while the situational features relevant for perceiving color properties are not (for instance, the lighting conditions). Lighting conditions are present in the scene and the world that is not location-relative. Therefore, the distinction between intrinsic color properties and the correlating situation-dependent properties cannot be analyzed in terms of the distinction between scenes and the world that is not location-relative. What we need is a distinction between scenes and the intrinsic properties in the relevant part of the uncentered world. That is just the distinction between situation-dependent and intrinsic properties. ${ }^{14}$

The very same two aspects that are involved in veridical perception can be argued to be involved in cases of illusion and hallucination, at least if the illusion or hallucination is of a seemingly colored and three-dimensional space-occupier. When one hallucinates an elf, one has a seeming point of view in relation to the elf. One can distinguish between the way the elf seems to fill out space from the way it seems to be presented given one's location. So the distinction between situation-dependent and intrinsic (hallucinated) properties holds for cases of illusion and hallucination in the very same way as it holds for cases of accurate perception.

Thinking about the ways objects are presented in terms of situationdependent properties makes it possible to acknowledge that as the situational features change, perceptual content remains the same with regard to the intrinsic properties of objects, but changes with regard to the situation-dependent properties. Furthermore, by understanding the ways objects are presented in terms of situation-dependent properties, the difference between how objects are presented and how one perceives

\footnotetext{
${ }^{14}$ With certain qualifications, situation-dependent properties could also be understood as what constitutes a centered world or in terms of centered properties. The distinction between a centered and an uncentered world is, however, only helpful to bring out the contrast between intrinsic spatial properties and the correlating situationdependent properties. It is not helpful to bring out the contrast between intrinsic colors or sounds and the correlating situation-dependent properties.
} 
them to be can be clearly brought out as a difference in what is perceived, and thereby distinguished from any differences in the ways in which an object, property, or relation is perceived. The point is to distinguish

(1) the way an object is presented given the situational features

from any

(2) mind-dependent objects or properties. ${ }^{15}$

The distinction between situation-dependent and intrinsic properties is not a distinction between the properties objects appear to have and the properties those objects actually have. Nor is it a distinction between the properties objects appear to have and the properties our experience represents objects as having. Since both intrinsic and situation-dependent properties are external and mind-independent, the distinction between them does not run parallel to the distinction between the properties of experience and the properties of objects. The distinction lies rather within the realm of external, minddependent properties of objects.

I am not arguing that every phenomenological difference should be understood in terms of a representational difference. Take Ernst Mach's example of perceiving a shape from the same angle once as a square and once as a diamond. The difference in perception is due to a difference in the way it is perceived. As Peacocke has argued, the way it is perceived contributes to what it is like to have the experience and is not captured in the representational content of perception. ${ }^{16}$ In such cases, there is no external difference to be represented and so the difference in phenomenology cannot be explained in terms of a difference in representations of mind-independent properties or objects.

I am arguing only that what is often understood solely in terms of mind-dependent properties or objects should be understood at least in part in terms of situation-dependent properties. When one changes one's location in relation to a shape, the way the shape is presented changes, that is, something external and mindindependent changes, namely the situation-dependent property of the object. In contrast to Mach's case, the change in the experi-

\footnotetext{
${ }^{15}$ The mind-dependent objects or properties can be understood for in stance in terms of sensational properties, appearance properties, or any number of minddependent ways that an object appears to a subject.

${ }^{16}$ See, for instance, his A Study of Concepts, pp. 74-77, and also his "Does Perception Have a Nonconceptual Content?," this Journal, XCVIII, 5 (May 2001): 23964 , p. $253 f$.
} 
ence due to the change in situational features can be explained with regard to the situation-dependency, rather than the subjectivity of perception. To a first approximation the subjectivity of experience can be understood as any aspect of experience that is a matter of mind-dependent properties or objects of the experience rather than the external, mind-independent objects and properties that the experience is of. The point of distinguishing the situationdependency from the subjectivity of perception is to contrast the properties of external objects from the properties of experience and the mind-dependent objects of experience.

Insisting that the ways objects are presented are mind-independent is of course not to deny that representations of these ways are minddependent. But it is crucial to distinguish

(3) representations of the way an object is presented given the situational features

from how the object appears to be and from the way the object is presented. How one represents objects as being presented is dependent on one's sensory system. Representations have been understood in many different ways. The present argument holds for any understanding that is committed to the most basic principle of characterizing perceptual content in terms of representations, namely, that there is a distinction between the case in which things are as they are represented to be and the case in which things are otherwise. In other words, the only principle that the use of representations here is committed to is that representations have accuracy conditions. ${ }^{17}$ This commitment is neutral on the question of whether perceptual content is conceptual or nonconceptual, whether perceptual content is propositional or image-like, or whether representational properties are pure or impure. ${ }^{18}$

In the interest of generality, I will not commit myself to a particular way of thinking about representations other than representa-

\footnotetext{
${ }^{17}$ In the context of this paper, I take for granted that experience is subject to accuracy conditions. This idea has been denied by adverbialists, such as Roderick Chisholm—see his Perceiving (Ithaca: Cornell, 1957). More recently, the thesis has been argued against by Charles Travis, "Silence of the Senses," Mind, cxiII, 449 (January 2004): 57-94; and by Bill Brewer, "Perception and Content," European Journal of Philosophy, xiv, 2 (August 2006): 165-81.

${ }^{18}$ Pure representational properties are properties of representing a content, while impure representational properties are properties of representing a content in a certain way. For a defense of this distinction, see Chalmers, "The Representational Character of Experience," in Brian Leiter, ed., The Future for Philosophy (New York: Oxford, 2004), pp. 153-81.
} 
tions having accuracy conditions. It is crucial, however, to be specific about what is represented when a subject has a scene in view. What one represents cannot simply reflect how objects are presented. It cannot be right that subjects, say, represent everything that they have in view. A myopic perceiver will represent less detail than someone with excellent vision given the very same scene, and a cat will represent something different from a human because its sensory apparatus is set up differently. Thus, what a subject represents must depend on what is perceptually available to her. What is perceptually available to a subject is determined by what could be perceptually discerned by her, which in turn is determined by her perceptual system. The number of leaves on a tree is, for example, not perceptually available to most humans, since our perceptual system does not have the capacity to perceive numbers of similar objects far beyond five. There is a further complication. Subjects are not necessarily aware of everything that is perceptually available to them. Say I see a tree swaying in the breeze. I might not be aware of the specific movement of a particular leaf fluttering in the breeze or a bug on one of the twigs, although these are details that are perceptually available to me and thus details of which I could be aware. So what is perceptually available must be determined dispositionally: for something to be perceptually available is for it to be something of which a subject can be perceptually aware given her perceptual system.

The important point for the present argument is that the differences in our perceptual systems affect only what we represent of a perceived scene. It does not affect the situation-dependent properties. It is crucial to distinguish both between what is there to be picked up and what one's perceptual system can pick up, as well as between what one's perceptual system in fact picks up and what one is perceptually conscious of. How one represents situation-dependent properties and what one represents when one has a particular scene in view depends on one's perceptual system. By contrast, the situation-dependent properties are there to be picked up regardless of whether one is the kind of perceiver that can pick them up and regardless of whether one actually does pick them up. In this respect, situation-dependent properties are just like intrinsic properties.

It will be helpful to work through an example. Consider Peacocke's example of two same-sized trees located at different distances from a subject. Peacocke analyzes the difference between the actual and the apparent sizes of the trees in terms of "a duality of representational properties and properties of the two-dimensional visual 
field." ${ }^{19}$ He identifies the properties of the two-dimensional visual field as sensational properties. So according to Peacocke, the difference between the perceptions of each tree is a difference in sensations, not a difference in representations.

By recognizing situation-dependent properties, at least part of what Peacocke understands as a difference in sensations can be reduced to a difference in representations of situation-dependent properties. So Peacocke's duality can be thought of as a duality within the representational properties. Such an approach allows one to think of the apparent difference in size not as an aspect of the visual field, but rather as an aspect of the world as it is presented to the perceiver's location. I am not denying that there is a visual field and I am not denying that the representations of situation-dependent properties could be matched by sensational properties. I am arguing that Peacocke's trees can be explained without appeal to the psychological notion of a visual field. They can be explained with regard to the world as it presents itself to the perceiver's location, that is, with regard to external, mind-independent, but situationdependent properties of objects. Since the situation-dependent properties are actual properties of the object given the situational features, one can say that there is a difference between the perception of the two trees with regard to the properties represented, and thus a difference in the externally individuated content of perception. In the veridical case, experience represents the trees as having the same intrinsic size properties, but as having different situation-dependent size properties. Once representations of situation-dependent properties are recognized, the apparent difference in size between the trees can be understood as a difference in situation-dependent properties. So once situation-dependent properties have been introduced, there is no need to appeal to sensational properties in the subject's visual field to explain the apparent difference in size of the two trees.

Now one could object that this leads to the problem that perception will represent the trees as both the same size and as different in size:

(a) (Tree ${ }_{1}$ and Tree $_{2}$ are different in size, Tree $_{1}$ and Tree $_{2}$ are the same size)

This cannot be the right way of characterizing the content since it would render the content incoherent. Since the situation-dependent properties will differ from the intrinsic properties in any standard

\footnotetext{
${ }^{19}$ Peacocke, Sense and Content: Experience, Thought, and Their Relations (New York: Oxford, 1983), p. 13.
} 
case of perception, most perceptual contents (so characterized) will exhibit a similar incoherence.

Since, however, the sense in which the two trees are different in size is distinct from the sense in which they are the same size, the content in the case at hand is not incoherent. When the two components of perceptual content are assessed, they are assessed relative to different aspects of the object (the object given the situational features, the object regardless of the situational features). The incoherence of (a) is just a way of describing the puzzle of perception that we are trying to come to grips with: one can perceive an object's intrinsic properties although the way an object is presented depends on the situational features. By showing that subjects represent both intrinsic and situation-dependent properties, it is possible to acknowledge that there is a sense in which perceiving the two trees as different in size is accurate: they really are presented as different in size given the subject's location in relation to the trees.

These considerations bring out a second problem with the way (a) characterizes the content in question. The two trees do not look to be both the same and different in size. They look to be the same size due to the fact that the closer tree is presented as larger than the tree that is further away. So the situation-dependent properties and intrinsic properties are not on par. One could try to account for the difference between the two properties by including more than the outcome of the function:

(b) (Tree ${ }_{1}$ and Tree $_{2}$ are different in size given the situational features, Tree $_{1}$ and Tree $_{2}$ are the same size)

This suggestion is similar to Gilbert Harman's suggestion. Harman argues that the "feature of a tree from here is an objective feature of the tree in relation to here, a feature to which perceivers are sensitive and which their visual experience can somehow represent things as having from here." ${ }^{20}$

The problem with the content characterized by (b) is that it involves more information than is required. The thesis that perception represents situation-dependent properties as well as intrinsic properties does not require that the situational features under which an object is perceived be represented. The specific angle at which one perceives a table or the precise brightness of the light are features that

\footnotetext{
${ }^{20}$ Harman, "The Intrinsic Quality of Experience," in James Tomberlin, ed., Philosophical Perspectives: Action Theory and Philosophy of Mind, Volume 4 (Northridge, CA: Ridgeview, 1990), pp. 31-52.
} 
are arguably not perceptually available, at least not to most human perceivers. More importantly, subjects can perceive the trees to be different in size given their location, without being aware of their location in relation to the trees. All that the situation-dependency thesis is committed to is that subjects represent situation-dependent properties and so the effect of situational features. This idea involves no commitment to saying that subjects represent situational features.

Another way of bringing out the issue is with regard to the difference between relational and monadic properties. Situationdependent properties can appear to be monadic properties. But a property can appear to be monadic and nonetheless reveal itself to be relational on reflection. ${ }^{21}$ Although situation-dependent properties are relational properties insofar as they are a function of intrinsic properties and situational features, they need not be represented as relational properties. Moreover the fact that they are relational properties need not reveal itself in the phenomenology of perception. One might want to take these considerations into account by characterizing the content in the following way:

(c) Tree $_{1}$ and Tree $_{2}$ are situation-dependently different in size, Tree 1 and $\mathrm{Tree}_{2}$ are intrinsically the same size)

This proposal is similar to Michael Tye's. ${ }^{22}$ Tye argues that "experience represents the nearer tree as having a facing surface that differs in its viewpoint-relative size from the facing surface of the further tree, even though it also represents the two trees as having the same viewpoint-independent size" (ibid., p. 124).

The problem with this characterization of the content is that the content represents whether a property is a situation-dependent property or an intrinsic property. Although human perceivers might typically be able to distinguish, say, the intrinsic shape of an object from the correlated situation-dependent property, it is easy to imagine a situation in which a subject is not able to tell whether a perceived property is intrinsic or situation-dependent. Tye goes on to argue that the nearer tree is represented as being larger from here. This idea implies that perceivers are aware not only whether a property is a situation-dependent property or an intrinsic property; it implies that perceivers are aware of the situational features.

\footnotetext{
${ }^{21}$ For a discussion of such features of properties, see Anil Gupta, "Meaning and Misconceptions," in Ray Jackendoff et al., eds., Language, Logic, and Concepts (Cambridge: MIT, 1999), pp. 15-41.

${ }^{22}$ Tye, "Perceptual Experience is a Many-Layered Thing," in E. Villanueva, ed., Philosophical Issues, Volume 7 (Atascadero, CA: Ridgeview, 1995), pp. 117-26.
} 
As I argued above this is cognitively too demanding a requirement for perception.

These problems can be avoided by characterizing the content in the following way:

(d) Tree $_{1}$ and Tree $_{2}$ are the same size', Tree 1 and Tree $_{2}$ are different in size")

Metaphysically speaking the single primed property is a situationdependent property and the double primed property is an intrinsic property. But perception need not represent these metaphysical facts.

An analogous analysis can be given for a case involving color properties. Consider a subject who is perceiving a blue couch in bright light. Due to the bright light, the couch is situationdependently green. The subject's perceptual content can be characterized in the following way:

(e) (that couch is blue', that couch is green")

This way of characterizing the content makes it possible to acknowledge that the situation-dependency thesis involves no commitment to subjects knowing whether a property is a situation-dependent property or an intrinsic property.

There are many possible ways of understanding the way situationdependent properties are reflected in the phenomenology of perception. My argument is agnostic on how this issue is conceived. I aim to establish that whatever stance is taken toward the way intrinsic properties are reflected in phenomenology should be taken towards the way situation-dependent properties are reflected in phenomenology. Whatever differences there are in phenomenology are arguably psychological differences: For human perceivers, intrinsic properties are usually more salient than situation-dependent properties. Therefore, they are typically in the foreground of our perceptual phenomenology. ${ }^{23}$

\footnotetext{
${ }^{23}$ David Chalmers discusses many possible ways of thinking about the phenomenology of the perceptual experience of a wall that is partially in shadow. See his "Perception and the Fall from Eden," in Gendler and Hawthorne, eds., Perceptual Experience, pp. 49-125; in particular pp. 84-89. His distinction between simple and complex phenomenology is particularly salient for the present discussion. On the simple view, only what I call situation-dependent properties are reflected in the phenomenology of an experience. On the complex view, the experience represents an intrinsic property in conjunction with a situational feature. As I have argued, this involves more information than required. The specific angle at which one perceives a table or the precise brightness of the light are features that are arguably not perceptually available, at least not to most human perceivers. I take it to be plausible that typically both situation-dependent properties and intrinsic properties are reflected in
} 
This analysis is congenial to William Lycan's argument ${ }^{24}$ that the apparent difference in the sizes of Peacocke's trees is represented in experience. However, it differs from his analysis insofar as my thesis is not understood to imply that something other than mindindependent properties, objects, and relations are represented. Lycan argues that perceptual representations have at least two layers. One is concerned with external, mind-independent physical objects, properties, and relations; the other is concerned with mind-dependent intentional objects and relational properties, namely colored shapes: "We do visually represent the trees as being of the same size etc., but we do that by representing colored shapes and relations between them. Some of the shapes-in particular those corresponding to the trees-are represented as being larger shapes than others, as occluding others, and so forth. As with all intentional objects, it does not follow that there are any actual things that have such relational properties" (ibid., p. 95). Lycan introduces a kind of mind-dependent intentional object to account for the two trees appearing different in size. He mirrors Hume's motivation for introducing such objects when he writes: "in Peacocke's example there are a veridical roadand-same-sized trees presentation and an illusory different-sizedtree-shapes presentation made in the same visual experience. The experience has one truth-condition that would be satisfied by the apparent different-sized shapes, and another that is satisfied by the same-sized tress. It happens that the former is actually not satisfied and in that sense there is an illusion" (ibid., p. 129). On Lycan's view, a subject's experience of the trees represents two same-sized trees as well as two intentional objects, one larger than the other. He argues that the representation of such intentional objects, say, a colored shape, need not imply that the colored shape exists. The shape is an object, but it is not an object that actually exists (ibid., p. 90).

Recognizing situation-dependent properties makes it possible to acknowledge that there is nothing illusory about representing the trees to be presented as different in size given the situation. Indeed given the situation, representing the trees to be presented as different in size is correct. Since situation-dependent properties are actual

the phenomenology of an experience. So my view suggests neither Chalmers's simple or complex view about phenomenology, but rather a third view. Call it the multiplex view. I will save a detailed discussion of the role that situation-dependent properties play in phenomenology for a future occasion.

${ }^{24}$ Lycan, "Layered Perceptual Representations," and "Replies to Tomberlin, Tye, Stalnaker, and Block," in Villanueva, ed. (op. cit.), pp. 81-100, 127-42. 
properties of the environment, the thesis that experience represents them involves no commitment to saying that experience represents anything other than mind-independent properties, objects, and relations. Recognizing situation-dependent properties is, however, compatible with Lycan's thesis that experience represents intentional objects. Similarly, one can recognize situation-dependent properties and nonetheless be a phenomenalist or an indirect realist. On such a view, there will be mind-dependent objects or properties that stand in representation relations to both intrinsic properties and to situation-dependent properties.

But although formally consistent with phenomenalism and indirect realism, recognizing situation-dependent properties undermines at least one traditional motivation for such views. As I argued earlier, one traditional motivation is that when a subject, say, moves away from a table something becomes smaller. Since it is not the table that becomes smaller, what is directly present to the mind must be something other than the table. If one recognizes situationdependent properties, no appeal to mind-dependent objects or properties is necessary to explain how there can be a way that objects look that is not accounted for by representing their external, mindindependent properties. Indeed, such cases are explained better with appeal to representations of two kinds of mind-independent properties: when one moves away from the table the situational features change while the intrinsic properties remain the same. The change in situation-dependent properties accounts for the change in the experience. If such cases are better explained with appeal to two kinds of mind-independent properties, then once situationdependent properties are introduced, the mind-dependent objects or properties are obsolete.

There are, however, other reasons to introduce mind-dependent objects or properties. One is that mind-dependent sensational properties are what make an experience an experience. ${ }^{25} \mathrm{~A}$ second is to account for the possibility that hallucinatory and veridical experiences are phenomenologically indistinguishable. ${ }^{26} \mathrm{~A}$ third is to account for the possibility of spectrum inversion. Sydney Shoemaker introduces appearance properties to reconcile the possibility of an intentionalist account of perception with phenomenal spectrum

\footnotetext{
${ }^{25}$ For a defense, see Peacocke, "Sensational Properties."

${ }^{26}$ I am following Timothy Williamson in using the expression of phenomenological indistinguishability to pick out an epistemic notion-Identity and Discrimination (Cambridge: Blackwell, 1990). On this understanding, for two experiences to be phenomenologically indistinguishable just is for the subject not to be able to distinguish them.
} 
inversion without misrepresentation. ${ }^{27}$ Take two subjects, one of which is spectrum inverted. Both subjects correctly represent a red tomato as red, but the phenomenology of their experiences differs. While one subject experiences the phenomenology that I experience when I am acquainted with red objects, the other subject experiences the phenomenology that I experience when I am acquainted with green objects. Representations of appearance properties are introduced to account for the difference in phenomenology. The subjects represent the tomato as having different appearance properties, but neither of them is misrepresenting. ${ }^{28}$ Appearance properties are either occurrent or dispositional properties. An occurrent appearance property is the property of currently producing a certain experience in a perceiver; a dispositional appearance property is a disposition to cause experiences of a certain sort in a kind of perceiver. According to Shoemaker, the phenomenal character of experience consists in the representation of either kind of appearance property. ${ }^{29}$

There are two parameters on which situation-dependent properties differ from appearance properties. While an appearance property "is such that something one sees has it just in case it appears to one to have it," ${ }^{30}$ a situation-dependent property is a property that a perceived object can have without one being conscious of it having the property. Put more simply, situation-dependent properties are properties that objects actually have given the situational features regardless of what any potential perceiver could pick up given its sensory capacities. So while appearance properties are relative to the sensory capacities of a potential perceiver, no reference to a perceiver (or a potential perceiver) is necessary to specify the situationdependent properties of an object.

The second difference concerns the question of how many kinds of properties are in the external, mind-independent realm. On Shoemaker's view, experience of colors requires representing properties

\footnotetext{
${ }^{27}$ Shoemaker used to call these properties "phenomenal properties" but has changed his terminology to "appearance properties." See his "Introspection and Phenomenal Character," Philosophical Topics, xxviı (2001): 247-73.

${ }^{28}$ For a critical discussion of Shoemaker's appearance properties as candidates for reconciling the possibility of spectrum inversion and intentionalism, see Andy Egan, “Appearance Properties?,” Noûs, xL, 3 (September 2006): 495-521.

${ }^{29}$ Recently, Shoemaker has argued that the phenomenal character sometimes does not consist in the representation of appearance properties, but rather in the representation of one or another of the aspects of perceivable properties that he calls qualitative aspects. See his "On the Way Things Appear." But like appearance properties, qualitative aspects are characterized in terms of how they affect or are disposed to affect the phenomenal character of experiences.

${ }^{30}$ Shoemaker, "On the Way Things Appear," p. 465.
} 
other than colors. Subjects perceive colors by perceiving properties distinct from them. As a consequence, each color experience ascribes two different properties (ibid., p. 467). Michael Thau defends a view in opposition to Shoemaker, according to which subjects perceive colors by ascribing only one property. ${ }^{31}$ Thau calls it a nameless intrinsic property. But like Showmaker, Thau argues that perception represents a property that is distinct from the color of the object that tells the perceiver about the color of the object. In contrast to both Shoemaker and Thau, I am arguing that experience of intrinsic colors requires representing two kinds of mind-independent, external properties of the object: intrinsic properties and situation-dependent properties. While appearance properties are relative to what a particular kind of perceiver can pick up, both intrinsic properties and situation-dependent properties are what are there to be picked up regardless of what a particular perceiver can pick up.

So what I am concerned about is orthogonal to Shoemaker's concerns. Indeed one can embrace situation-dependent properties along with Shoemaker's appearance properties or any other kind of minddependent properties. The mind-dependent properties will stand in representation relations both to intrinsic properties and to situationdependent properties.

But what is the advantage of recognizing situation-dependent properties if one already has mind-dependent properties in place? There are several advantages, which I will discuss in turn. One advantage is that it makes it possible to recognize that more of experience is subject to accuracy conditions than is traditionally acknowledged. For an experience to be accurate it must not just get the intrinsic properties of an object right, but also its situation-dependent properties. The ways objects are presented given the situational features makes a difference to which perception it is. Perceptions are individuated more finely than by objects and their intrinsic properties; they are individuated also by situation-dependent properties. ${ }^{32}$ If perceptions are not just individuated by the objects they are of, but by the way those objects are presented, then individuation of perceptual content nec-

\footnotetext{
${ }^{31}$ See Thau's Consciousness and Cognition (New York: Oxford, 2002).

${ }^{32}$ Tye rejects the idea that perception is individuated by objects and their properties-Consciousness, Color, and Content (Cambridge: MIT, 2000), and earlier in Ten Problems of Consciousness (Cambridge: MIT, 1995). He argues that perception is individuated by its functional role. In the context of this paper, I am taking for granted that perceptual content is individuated by the properties and objects that the perception is of. This thesis (and thus my argument) is compatible with both externalism and internalism about perceptual content. Furthermore, the thesis is compatible with perception also being individuated by the phenomenal character of the experience.
} 
essarily requires appeal to facts about the situation in which the object is presented. If this is right, then perception involves representations not just of an object's intrinsic properties, but also of its situationdependent properties. As a consequence, to assess whether an experience is accurate is not only to assess whether the right intrinsic properties are represented, but also to assess whether the right situation-dependent properties are represented. This is just to say that the satisfaction of the accuracy conditions depends on accurately representing both the object's intrinsic properties and its situationdependent properties. If situation-dependent properties are external and mind-independent properties, then they can be represented and misrepresented in just the way that intrinsic properties can be represented and misrepresented.

In contrast to situation-dependent properties, mind-dependent properties cannot strictly speaking be misrepresented. No doubt, one can say that how things appear or seem to a subject $S$ is accurate if, and only if, things are as they appear. So if it appears to $S$ that there is something green before $S, S$ 's experience is accurate if, and only if, there is before $S$ a physical object with a green surface. But that is not to deny that it is true that things appear to $S$ in that way. ${ }^{33}$ In other words, how things appear to $S$ is not the kind of thing that $S$ can be wrong about.

A second advantage is that it makes it possible to accommodate the fact that there is a wide range of viewing conditions or situational features that can count as normal. ${ }^{34}$ Situation-dependent properties change as the situational features change, while intrinsic properties remain constant.

In the rest of the paper, I will elaborate on two further advantages. But first it is important to bring out one important consequence of the situation-dependency thesis. If one recognizes situation-dependent properties, then many cases of perceptual experiences that in the philosophical literature are typically categorized as illusory or as misrepresentations will turn out to be accurate perceptions-at least

\footnotetext{
${ }^{33}$ It should be noted that D.M. Armstrong and others have argued that one can be wrong about how things appear to one-see his A Materialist Theory of the Mind (New York: Routledge 1968). For a discussion of the problem of misrepresenting appearance properties, see Egan, p. 16 and also p. 22, as well as Allen (manuscript). It would lead too far afield to discuss introspective fallibility and the possibility of misrepresenting appearance properties here. I will save it for another occasion.

${ }^{34}$ For discussion, see Hardin. Among many others, Wilfird Sellars's account of perception relies on the idea of normal viewing conditions. See his Empiricism and the Philosophy of Mind, with an introduction by Richard Rorty and a Study Guide by Robert Brandom (Cambridge: Harvard 1977).
} 
with regard to their representations of situation-dependent properties. Take the stick partially immersed in water. Given the situational features the stick appears to be bent. Due to the different refraction index of water and air, the stick is presented as bent. The stick is not bent, but it is accurate to perceive it to be presented as bent given the situational features.

Some illusions will retain their status, for instance, the Müller-Lyer illusion and similar psychological illusions. The reason why one perceives one stick as longer than the other despite the fact that they are the same length is not due to representing two different situationdependent properties. The reason for the illusion is rather the Gestalt principles of convergence and divergence: the lines at the sides lead the eye either inward or outward thereby creating a false impression of length.

This points to an important limit of the situation-dependency thesis. I take it that only basic intrinsic properties such as shapes, colors, sounds, and surface structures ${ }^{35}$ have correlating situationdependent properties. The same is not true of high-level perceivable properties such as being happy, beautiful, or dangerous. This disanalogy does not, however, imply that the situation-dependency thesis is restricted to perception of basic properties since, arguably, perception of high-level properties is dependent on perception of basic properties. If this is right, then every event of perception will include perception of basic properties. As a consequence, the situation-dependency thesis holds for all events of perception.

III. THE ARGUMENT FOR THE EPISTEMIC DEPENDENCE THESIS

I have argued that the ways objects are presented can be understood as external, mind-independent, albeit situation-dependent properties of objects. Only if perceptual knowledge of intrinsic properties can be shown to be epistemically dependent on representations of the relevant situation-dependent properties, can the suggested view, however, be any better than naïve direct realism. Call the thesis that perceptual knowledge of intrinsic properties is epistemically dependent on representations of the relevant situation-dependent properties the epistemic dependence thesis. The intuition on which this thesis is grounded is that one perceives an object's intrinsic properties precisely because of the way the object is presented. One per-

\footnotetext{
${ }^{35} \mathrm{My}$ argument has focused on the case of visual perception, but I take it to extend to all sensory modalities. It would lead too far afield to go into the specifics of all sensory modalities here. The argument only extends to taste and olfaction under particular assumptions of what the objects are of these two sensory modalities. Thanks to Rachael Brown and Kim Sterelny for discussions on olfaction.
} 
ceives a table to remain constant in size as one moves away from it precisely because it fills out less of one's visual field. And one perceives the rectangular shape of the table precisely because of the way the shape is presented in one's egocentric frame of reference. Similarly, one perceives a uniformly white wall to be uniformly white precisely because it is presented the way white walls are presented in the very lighting conditions under which one is perceiving it.

There are many kinds of dependency relations. No one denies that if a subject $S$ sees a material object $o$, then $o$ causally affects $S$. Arguably, what is causally relevant is what I call the situationdependent properties of the object. Naive direct realists can acknowledge such a causal dependence. But by arguing that it plays a role only on a subpersonal level, they can deny that it is of any significance for a philosophical account of perceptual knowledge.

Regardless of how one stands on the question of a causaldependence, there is, I will argue, an epistemic dependence of perceptual knowledge of intrinsic properties on representations of situation-dependent properties. The epistemic priority of the ways objects are presented given the situational features is due to the spatiotemporal nature of perception. Subjects differ dramatically in the way their sensory organs are spatially extended. One can imagine subjects who can perceive an object from several angles simultaneously. The way the sensory organs are spatially extended depends on the particular kind of perceiver. But it is a necessary feature of perception that subjects perceive from somewhere at some time. If one necessarily perceives objects from a particular location at a particular time, then the way an object is presented depends on the situational features. As I will show, it follows from this that representations of situation-dependent properties are the basis for knowledge of intrinsic properties. Another way of expressing the same point is that they are what James Pryor calls "justificationmaking conditions" for perceptual knowledge of intrinsic properties. ${ }^{36}$ Consider again Peacocke's trees. The nearer tree is presented as larger than the tree that is further away. This difference in size with regard to their situation-dependent properties is the basis for her perceptual knowledge that the trees are the same size. The subject has experiential evidence that the two trees are the same size. This evidence is, however, parasitic on her evidence that the nearer tree is presented as larger than the tree that is further away from her. Both

\footnotetext{
${ }^{36}$ Pryor, “There Is Immediate Justification," in Ernest Sosa and Matthias Steup, eds., Contemporary Debates in Epistemology (Malden, MA: Blackwell, 2005), pp. 181-201, especially, p. 182.
} 
layers of evidence are liable to defeat. However, if evidence for the situation-dependent properties is defeated, the subject's evidence for the intrinsic properties is defeated, but not vice versa. Defeaters can be understood in two ways. While undercutting defeaters block the line of evidence from which the warrant actually arises, rebutting defeaters provide independent lines of evidence warranting the contrary conclusion. If the subject's evidence for the situation-dependent properties is defeated, then her evidence for the intrinsic properties is undercut (and not just rebutted). It follows from this that the asymmetry of defeat is grounded in an asymmetry of warrant. It is because the evidence for the situation-dependent property is in the line of evidence for the intrinsic property that defeat of the former entails defeat of the latter. And it is because the evidence for the intrinsic property is not in the line of evidence for the situation-dependent property that defeat of the former does not entail defeat of the latter. Thus, evidence for intrinsic properties is dependent on evidence for situation-dependent properties both with regard to defeat and warrant.

This relation of epistemic dependence implies that perceptual knowledge of intrinsic properties is mediated by representations of situation-dependent properties. It need not imply, however, that subjects arrive at perceptual knowledge of intrinsic properties by a conscious inference $e^{37}$ or that intrinsic properties are not perceptually available. The whiteness of the wall to my right and the roundness of the rim of the cup before me are perceptually available to me. ${ }^{38}$

Furthermore, the thesis that there is an epistemic primacy to situation-dependent properties does not imply that they are primary in perceptual consciousness. One could deny that when perceiving an object one is at all aware of how it is presented given the situational features: perceptual awareness is simply of the intrinsic properties. Intuitions diverge strongly on whether perceptual awareness includes the shadow play on the wall over and above the whiteness of the wall. Certainly when perceiving a white wall humans typically do not attend to the details of the shadows cast on the wall. But sometimes one does attend to the shadows, for instance, when one takes a realistic painter's point of view. The important point for the present discussion is that even if one's attention is directed at an object's intrinsic properties, one can be aware of the way the object is presented.

\footnotetext{
${ }^{37}$ For discussion, see McDowell, "Criteria, Defeasibility and Knowledge," Proceedings of the British Academy, LXVIII (1982): 455-79.

${ }^{38}$ I argue for a way of understanding how a subject moves from representations of situation-dependent spatial properties to representations of intrinsic spatial properties in my "Action and Self-Location in Perception."
} 
Certainly, when one's location in relation to an object changes, one is typically aware of something changing regarding the shape or size of the object. The argument for the situation-dependency of perception requires that it is possible to be aware of the situation-dependent properties of an object without attending to them. But it does not depend on how the details of the relation between awareness and attention are resolved. There are many ways of understanding the relation between awareness and attention. ${ }^{39}$ One that seems particularly conducive to the present discussion is Bill Brewer's distinction between foreground and background awareness. ${ }^{40}$

The fact that intrinsic rather than situation-dependent properties typically occupy the attention of human perceivers may appear to stand in conflict with the thesis that there is an epistemic primacy to situation-dependent properties. But it is important to distinguish between what is primary in perceptual consciousness from what is causally primary and what is epistemically primary. I am arguing only that situation-dependent properties are epistemically primary. Epistemic primacy can but need not be understood to entail causal primacy. ${ }^{41}$ Regardless of how one stands on the relation between epistemic and causal primacy, no implication about phenomenological primacy follows from either epistemic or causal primacy. The epistemic dependency thesis does not imply that situation-dependent properties are in the foreground of a subject's perceptual awareness, although it is of course possible that they are. The thesis is even compatible with the claim that subjects are not aware of situationdependent properties, at least if one accepts that for a subject to have evidence, the subject need not be aware of this evidence. ${ }^{42}$ If a subject can have evidence without being aware of this evidence, then the fact that intrinsic properties typically occupy the attention of at least human perceivers does not stand in conflict with the thesis that perceptual knowledge of the whiteness of the wall is epistemically depen-

\footnotetext{
${ }^{39}$ For helpful accounts of this distinction, see Campbell, Reference and Consciousness (New York: Oxford, 2002), and Ned Block, "Mental Paint," in Martin Hahn and Bjørn Ramberg, eds., Reflections and Replies: Essays on the Philosophy of Tyler Burge (Cambridge: MIT, 2003), pp. 165-200.

${ }^{40}$ See Brewer, Perception and Reason (New York: Oxford, 1999), especially sections 5.3.1 and 7.4.3.

${ }^{41}$ For a defense of the idea that epistemic dependence entails causal dependence, see Hilary Kornblith, "Naturalizing Rationality," in Newton Garver and Peter H. Hare, eds., Naturalism and Rationality (Buffalo, NY: Prometheus, 1986), pp. 115-33. For a critical discussion of the thesis, see Robert Audi, The Structure of Justification (New York: Cambridge, 1993), pp. $99 \mathrm{ff}$.

${ }^{42}$ Michael Bergmann argues that a subject's belief can be justified by something even if the subject is not aware of that thing. See his Justification without Awareness (New York: Oxford, 2006), especially chapter 1.
} 
dent on representing the way it is presented given the lighting conditions. I take it to be plausible that subjects are always to some extent aware of situation-dependent properties, but my thesis does not depend on it. ${ }^{43}$

By pulling apart what is epistemically primary from what is phenomenologically primary the suggested view differs from both standard direct and indirect realist views. On both views, the properties and objects that are epistemologically primary are also phenomenologically primary. According to naïve direct realists intrinsic properties are argued to be both epistemologically and phenomenologically prior. According to indirect realism, what is directly present to the mind is argued to be a mind-dependent object or property (that correlates to what I call situation-dependent properties). Arguably, indirect realists are committed to the thesis that these mind-dependent objects or properties are both phenomenologically and epistemologically prior. Because on the suggested view there are two kinds of external, mind-independent properties, what is epistemologically prior need not coincide with what is phenomenologically prior.

Now, it is empirically well established that the process of bringing about representations of situation-dependent and intrinsic properties are mutually dependent in the human visual system insofar as information about situation-dependent properties is used to gain information about intrinsic properties and vice versa. ${ }^{44}$ Acknowledging this fact is compatible with accepting the epistemic dependency thesis insofar as the epistemic dependence between the two representations is independent of the process by which these representations are brought about. The epistemic dependence is not a matter of how the visual system arrives at the representations but a matter of the relations of defeasibility and warrant.

I have argued that perceptual knowledge of intrinsic properties is epistemically dependent on representing situation-dependent prop-

\footnotetext{
${ }^{43}$ It has been argued that concepts such as "is red" should be analyzed in terms of concepts used to pick out sense-experiences, such as "looks red." The question of whether representations of intrinsic properties are epistemically dependent on representations of situation-dependent properties is orthogonal to the question of any semantic dependence of "material-object" predicates on "looks"-predicates. For different versions of this thesis, see Chisholm; and see Roderick Firth, "Coherence, Certainty, and Epistemic Priority," this Journal, LXI, 19 (October 1964): 545-57. For a critical discussion, see Sellars, "Givenness and Explanatory Coherence," this JOURNAL, LXX, 18 (October 1973): 612-24.

${ }^{44}$ Thanks to Kim Sterelny for pressing me on this point. For an excellent discussion of the processing relation between viewpoint-invariant and viewpoint-relative representations, see Jesse Prinz, Furnishing the Mind (Cambridge: MIT, 2002), in particular chapters 6 and 7 .
} 
erties. It is important to note that the epistemic dependency thesis does not require that the representations of situation-dependent properties constitute knowledge. The thesis is weaker: representations of situation-dependent properties are the basis for knowledge of intrinsic properties. So I am presupposing that evidence need not constitute knowledge. Moreover, I take it to be plausible that representations of situation-dependent properties need not have a propositional structure. My thesis is, however, neutral on this issue. If, however, representations of situation-dependent properties do not constitute propositions, then the epistemic dependency thesis can only be true if evidence for knowledge does not require that this evidence is propositional. ${ }^{45}$

I have argued that perceptual knowledge of the intrinsic properties of an object is epistemically dependent on representing the relevant situation-dependent properties. If representing intrinsic properties is dependent on representing their situation-dependent properties, then the representation of situation-dependent properties must be a necessary part of perceptual content. So perceptual content will crucially differ from the content of a thought about the same object insofar as a thought about an object does not necessarily represent the object's situation-dependent properties. ${ }^{46}$

There are many other ways of thinking about the difference between perceptual content and the content of thought. One is to say that the fundamental difference between perception and thought is that there are phenomenal or sensational properties present in perception but not in thought. ${ }^{47}$ Another is to say that the difference between the content of perception and the content of thought is a structural or functional difference. Robert Brandom argues, for instance, that the role of thoughts in language is inferential, while the role of perceptions is noninferential. ${ }^{48}$ According to McDowell, ${ }^{49}$ we employ the very same conceptual capacities passively in experience

\footnotetext{
${ }^{45}$ It is typically taken for granted that evidence need not constitute knowledge and need not be propositional-recently, for instance, by Bergmann. Williamson argues that all evidence is knowledge and that all evidence is propositional-Knowledge and Its Limits (New York: Oxford, 2000). It would go well beyond the scope of this paper to consider Williamson's argument here.

${ }^{46}$ Demonstrative thoughts are a special case. Arguably they are based on perception and to that extent mirror the situation-dependency of perception.

${ }^{47}$ There are exceptions: Terence Horgan and John Tienson argue that mental states, such as beliefs and desires, have phenomenal character as well, See their "The Intentionality of Phenomenology and the Phenomenology of Intentionality," in Chalmers, ed., Philosophy of Mind (New York: Oxford, 2002), pp. 520-33.

${ }^{48}$ See Brandom's Making It Explicit (Cambridge: Harvard, 1994), chapter 4.

${ }^{49}$ See McDowell's Mind and World.
} 
that we employ actively in thoughts. Fred Dretske distinguishes the content of experience and thought with regard to the origin of their functions. ${ }^{50}$ According to Tye,${ }^{51}$ thoughts are representations in a linguistic medium, while experiences are representations in an imagelike medium. I stay agnostic on whether perception and thought differ phenomenally and whether their content differs structurally or functionally over and above the difference in what is represented. If the argument I have given holds at all, it holds regardless of what stance one takes on these other possible differences.

\section{THE ARGUMENT FOR THE DIRECT PERCEPTION THESIS}

Due to the role of appearances in the tradition of Locke, Berkeley, and Hume, the idea that objects are presented a certain way has been considered to be at odds with the intuition that we directly perceive objects. The notion of direct perception has been understood in many different ways. As I understand it, one perceives an object directly if one does not perceive it in virtue of perceiving another thing. This conception must be contrasted with a notion according to which to perceive something directly would be to be perceptually aware of it without bringing any capacities to bear on what is given in perception that are not narrowly construed sensory capacities. ${ }^{52}$

If the ways objects are presented given the situational features are distinguished both from how they appear to be and from representations of the ways objects are presented, then there is no conflict between the intuition that we perceive objects directly and the claim that objects are presented a certain way given the situational features. Since situation-dependent properties are actual properties of an object, we perceive an object directly by perceiving its situationdependent properties directly.

The objection could be raised that this way of thinking about perception is committed to an epistemic intermediary and thus subject to the very same objections that can be raised against indirect realism. According to indirect realism, one perceives objects in-

\footnotetext{
${ }^{50}$ See Dretske's Naturalizing the Mind (Cambridge: MIT, 1995).

${ }^{51}$ See Tye's Consciousness, Color, and Content.

${ }^{52}$ The first understanding has been considered a non-epistemological characterization of direct perception, the second an epistemological characterization of direct perception (see, for instance, Jackson, Perception). There are other ways of characterizing direct perception epistemologically, the differences depending largely on what one means by epistemological. Paul Snowdon characterizes an epistemological understanding of direct perception as the idea that something is directly perceived if and only if it is noninferentially known-see his "How to Interpret 'Direct Perception'," in Tim Crane, ed., The Contents of Experience (New York: Cambridge, 1992), pp. $48-78$.
} 
directly by having a special kind of mind-dependent object present to mind. Arguably, such a view introduces an epistemic intermediary between one's perception and the physical objects that one's perception is of, thereby cutting us off from reality. One could say that if one perceives the intrinsic properties of objects in virtue of perceiving their situation-dependent properties, then one is similarly cut off from the object as it is.

In contrast to the mind-dependent items that the indirect realist invokes, situation-dependent properties do not constitute an object that is distinct from the physical object in view. The situationdependency thesis does not involve a commitment to any object over and above the physical object that one's perception is of. An object's intrinsic properties and its situation-dependent properties are properties of the very same object. Therefore, acknowledging situation-dependent properties makes it possible to account for the ways objects are presented while maintaining that subjects perceive objects directly. Subjects perceive objects directly in virtue of perceiving their situation-dependent properties directly. So the suggested way of thinking about perception differs fundamentally from indirect realist views. While the indirect realist argues that we perceive physical objects indirectly by having something mind-dependent present to mind, the thesis presented here is that we perceive objects directly by perceiving their situation-dependent properties directly.

This will not impress a skeptic. But the point of understanding how objects are presented as external and mind-independent is not to fend off skeptical worries. The point is rather to show that much of what is typically thought of in terms of the subjectivity of perception should rightly be thought of in terms of the situation-dependency of perception. Skeptical worries arise for the situation-dependent properties in just the way that they arise for the existence of an external world, precisely because they are elements of the external world.

\section{CONCLUSION}

My aim was to show that in order to explain how perception can give us knowledge of objects, the way one gains knowledge through perception must be taken seriously. The way one gains knowledge through perception is by being presented with objects given situational features, such as the lighting conditions and one's location in relation to the object. If this is right, then perception is necessarily situation-dependent. I spelled out this situation-dependency thesis by arguing that the ways objects are presented can be understood in terms of situation-dependent properties: external, mindindependent properties that an object has given the situational features. 
I argued that recognizing situation-dependent properties yields four advantages. First, it makes it possible to acknowledge that perceptual experiences are not just individuated by the objects they are of, but by the ways those objects are presented given the situational features. On standard views, the conditions an experience must satisfy to be accurate is only to attribute the right intrinsic properties to the right object: the way the object is presented does not matter for whether the experience is accurate. In contrast to such views, I have argued that the ways objects are presented are the kind of things that can be represented and misrepresented in just the way that intrinsic properties can be represented and misrepresented. By understanding the ways objects are presented in terms of mind-dependent, situationdependent properties we can recognize that more of experience is subject to accuracy conditions than standard views acknowledge. The conditions an experience must satisfy to be accurate is not just to get the intrinsic properties right, but is also to get the situationdependent properties right. So the ways objects are presented are objective contents of subjective acts of consciousness in the very same way as objects and their intrinsic properties are objective contents of subjective acts of consciousness. Insofar as situation-dependent properties can be represented and misrepresented in the very same way that intrinsic properties can be represented and misrepresented, they are systematically related to the content of states that ground our beliefs about the world.

Second, recognizing situation-dependent properties allows for a way to accommodate the fact that there is a wide range of viewing conditions or situational features that can count as normal. Situationdependent properties change as the situational features change, while intrinsic properties remain constant.

Third, I argued that perceiving the intrinsic properties of objects is epistemically dependent on representing their situation-dependent properties. If perceiving the intrinsic properties of objects is epistemically dependent on representing their situation-dependent properties, then representations of situation-dependent properties are a necessary part of perceptual content. Insofar as perceptual content necessarily involves representations of situation-dependent properties, it crucially differs from the content of a thought about the same object.

Finally, recognizing situation-dependent properties makes it possible to embrace the motivations that lead to phenomenalism and indirect realism by recognizing that objects are presented a certain way, while holding on to the intuition that subjects directly perceive objects. The suggested way of thinking about perception is 
similar to an indirect realist approach in that perceiving the intrinsic properties of objects is dependent on perceiving something else. In contrast to an indirect realist approach the intermediary is, however, not a subjective, mind-dependent intermediary. The intermediary is rather a second kind of external, mind-independent property of the very same object, namely a situation-dependent property. Perception of intrinsic properties is dependent on perception of situationdependent properties.

Views according to which perception involves representations of mind-dependent properties (or objects) can recognize situationdependent properties. If they do, there will be mind-dependent properties (or objects) that stand in representation relations both to intrinsic properties and to situation-dependent properties. But although formally consistent with such views, recognizing situationdependent properties undermines at least one central motivation that has traditionally led to such views. If one recognizes situationdependent properties, no appeal to mind-dependent properties is necessary to explain how it can be that there is a way that objects look that is not accounted for by representing their intrinsic properties. If this is the reason for introducing mind-dependent properties (or objects), then one might as well drop them once situation-dependent properties are acknowledged.

Australian National University

SUSANNA SCHELLENBERG 